\title{
Piperlongumine Induces Apoptosis and Synergizes with Cisplatin or Paclitaxel in Human Ovarian Cancer Cells
}

\author{
Li-Hua Gong, ${ }^{1}$ Xiu-Xiu Chen, ${ }^{1}$ Huan Wang, ${ }^{2}$ \\ Qi-Wei Jiang, ${ }^{3}$ Shi-Shi Pan, ${ }^{1}$ Jian-Ge Qiu, ${ }^{3}$ Xiao-Long Mei, ${ }^{3}$ You-Qiu Xue, ${ }^{3}$ \\ Wu-Ming Qin, ${ }^{3}$ Fei-Yun Zheng, ${ }^{1} \mathrm{Zhi} \mathrm{Shi}^{3}$ and Xiao-Jian Yan ${ }^{1}$ \\ ${ }^{1}$ Department of Gynecology, The First Affiliated Hospital of Wenzhou Medical College, Shangcai Village South, \\ Ouhai District, Wenzhou, Zhejiang 325000, China \\ ${ }^{2}$ Department of Gynecology, The Third Affiliated Hospital of Sun-Yat Sen University, Guangzhou, Guangdong 510632, China \\ ${ }^{3}$ Department of Cell Biology and Institute of Biomedicine, College of Life Science and Technology, Jinan University, Room 708, \\ The 2nd Engineer and Scientific Building, 601 Huangpu RoadWest, Guangzhou, Guangdong 510632, China
}

Correspondence should be addressed to Zhi Shi; tshizhi@jnu.edu.cn and Xiao-Jian Yan; yxjbetter@126.com

Received 14 February 2014; Revised 1 April 2014; Accepted 3 April 2014; Published 8 May 2014

Academic Editor: Si Jin

Copyright (C) $2014 \mathrm{Li}-\mathrm{Hua}$ Gong et al. This is an open access article distributed under the Creative Commons Attribution License, which permits unrestricted use, distribution, and reproduction in any medium, provided the original work is properly cited.

\begin{abstract}
Piperlongumine (PL), a natural alkaloid from Piper longum L., possesses the highly selective and effective anticancer property. However, the effect of PL on ovarian cancer cells is still unknown. In this study, we firstly demonstrate that PL selectively inhibited cell growth of human ovarian cancer cells. Furthermore, PL notably induced cell apoptosis, G2/M phase arrest, and accumulation of the intracellular reactive oxidative species (ROS) in a dose- and time-dependent manner. Pretreatment with antioxidant $\mathrm{N}$-acety-L-cysteine could totally reverse the PL-induced ROS accumulation and cell apoptosis. In addition, low dose of PL/cisplatin or paclitaxel combination therapies had a synergistic antigrowth effect on human ovarian cancer cells. Collectively, our study provides new therapeutic potential of PL on human ovarian cancer.
\end{abstract}

\section{Introduction}

Ovarian cancer is the most lethal cancer of female reproductive tract, accounting for $\sim 16,000$ deaths annually [1]. The high mortality results partially from the nonspecific and commonly misinterpreted symptoms associated with the disease. As a result, more than $70 \%$ of patients are diagnosed only after the disease has progressed to a late stage [2]. Cytoreduction surgery combined with cisplatin (DDP) or paclitaxel (TX) chemotherapy in ovarian cancer results in a clinical remission but is infrequently a cure. Improving the current responses to chemotherapy is a key for achieving a better outcome and we have demonstrated that silence of survivin could effectively increase the sensitivity of ovarian cancer cells to chemotherapeutical drugs [3-6]. Etiology of ovarian cancer is still unknown; several theories such as gonadotropin theory and genetic alteration have been proposed as the mechanism of carcinogenesis [7]. A role for chronic oxidative stress has been proposed in the etiology of malignant transformation and elevation of reactive oxygen species (ROS) levels has been observed in many cancer cells relative to nontransformed cells $[8,9]$. Therefore, the elevated ROS in cancer cells provide for a prospect of selective cancer treatment $[10,11]$.

Piperlongumine (PL) is a biologically active alkaloid isolated from the long pepper (Piper longum Linn) which is used to treat cough, respiratory infections, stomachache, and other diseases in Indian Ayurvedic medicine [12]. The chemical structure of PL has been well-characterized (Figure 1(a)). Recently, PL has shown potential cytotoxic and antitumor properties on several types of cancer cells, including hematological [13], gastrointestinal [14], central nervous system [15], and other solid tumors [16]. Its cytotoxicity was observed in the micromolar range in tumor cells, but not in normal cells 
<smiles>COc1cc(/C=C/C(=O)N2CCC=CC2=O)cc(OC)c1OC</smiles>

(a)

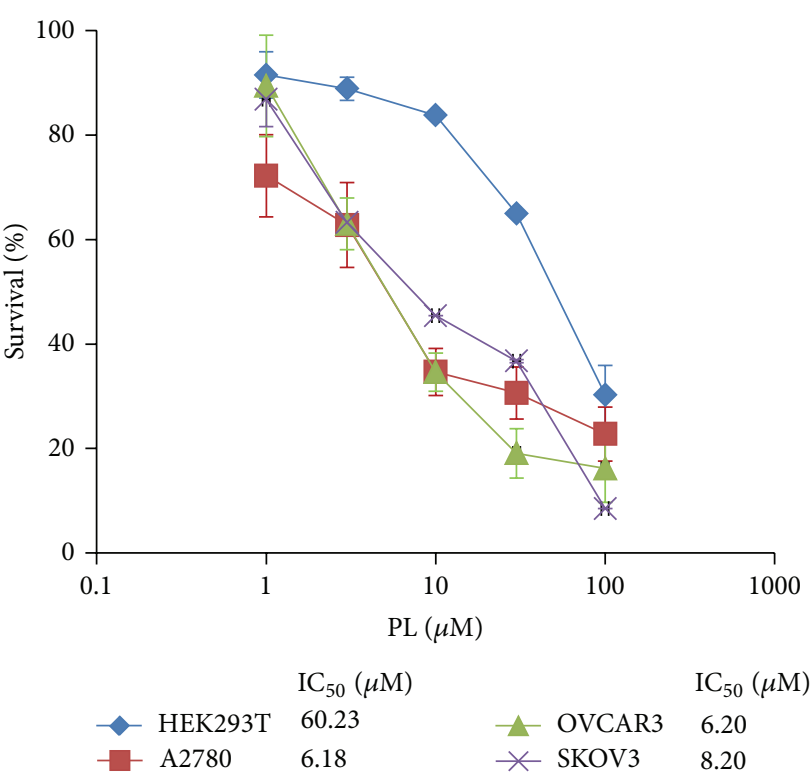

(b)

FIGURE 1: PL selectively inhibited the growth of human ovarian cancer cells. (a) Structure of PL. (b) The growth curves of PL-treated A2780, OVCAR3, SKOV3, and HEK293T cells. Cells were grown in 96-well plates for $24 \mathrm{hr}$ and treated with PL $(0,1,3,10,30$, and 100 $\mu \mathrm{M})$ for $72 \mathrm{hr}$. Cell survival was measured by MTT assay and the $\mathrm{IC}_{50}$ value of PL in each cell lines was calculated.

[14, 16-18]. Quantitative proteomics approaches identified two strong PL-binding proteins, S-transferase pi 1 (GSTP1) and carbonyl reductase 1 , known to regulate oxidative stress by modulating redox and ROS homeostasis [18]. Consistent with this theory, when PL interacted directly with GSTP1, protein glutathionylation was identified as a process associated with cellular toxicity [19]. Furthermore, PL induced cell cycle arrest in G1 or G2/M phase followed by mitochondrialdependent apoptosis [20]. More recently, PL also promoted autophagy and mediates cell death in several cancer cell lines [21, 22].

In the present study, we firstly demonstrate that PL selectively inhibited cell growth and induced ROS-dependent cell apoptosis and G2/M cell cycle arrest in human ovarian cancer. Furthermore, PL synergizes with DDP and TX to inhibit the growth of human ovarian cancer cells. Our results provide new drug therapeutic potential of PL on human ovarian cancer.

\section{Materials and Methods}

2.1. Cells Lines and Reagents. The human epithelia ovarian cancer (EOC) lines A2780, OVCAR3, and SKOV3 and human embryonic kidney cell line HEK293T were cultured in DMEM (Gibco, NY, USA) culture medium supplemented with $10 \%$ fetal bovine serum (Gibco, NY, USA) at $37^{\circ} \mathrm{C}$ and $5 \% \mathrm{CO}_{2}$. PL, N-acetyl-L-cysteine (NAC), dihydroethidium (DHE), anti- $\beta$-actin antibody, and other chemicals were purchased from Sigma Chemical Co. (St. Louis, MO, USA). Anticleaved-PARP (C-PARP) antibody was from Cell Signaling Technologies (Danvers, MA, USA).
2.2. MTT Assay. Cells were harvested with trypsin and resuspended in a final concentration of $5 \times 10^{4}$ cells $/ \mathrm{mL}$. Aliquot $(100 \mu \mathrm{L})$ for each cell suspension was distributed evenly into 96-well multiplates. The different concentrations of PL (10 $\mu \mathrm{L} /$ well) were added to designated wells. After 72 hours (hr), $10 \mu \mathrm{L}$ of 3-(4,5-dimethylthiazol-2yl)-2,5-diphenyl tetrazolium bromide (MTT) solution $(5 \mathrm{mg} / \mathrm{mL})$ was added to each well, and the plate was further incubated for $4 \mathrm{hr}$, allowing viable cells to change the yellow MTT into dark-blue formazan crystals. Subsequently, the medium was discarded and $100 \mu \mathrm{L}$ of dimethylsulfoxide (DMSO) was added to each well to dissolve the formazan crystals. The absorbance in individual well was determined at $490 \mathrm{~nm}$ by multidetection microplate reader 680 (BioRad, PA, USA). The concentrations required to inhibit growth by $50 \%\left(\mathrm{IC}_{50}\right)$ were calculated from survival curves using the Bliss method [23, 24]. For drug combination experiments, cells were cotreated with different concentrations of PL and DDP or TX for $72 \mathrm{hr}$. The data were analyzed by CompuSyn software with the results showed in combination index (CI) values, where $\mathrm{CI}<1,=1$, and $>1$ indicate synergism, additive effect, and antagonism, respectively.

2.3. Apoptosis Analysis. Cell apoptosis was evaluated with flow cytometry (FCM) assay. Briefly, cells were harvested and washed twice with cold phosphate-buffered saline (PBS), stained with Annexin V-FITC and propidium iodide (PI) in the binding buffer, and detected by FACSCalibur FCM (BD, CA, USA) after $15 \mathrm{~min}$ incubation at room temperature in the dark. Fluorescence was measured at an excitation wave 

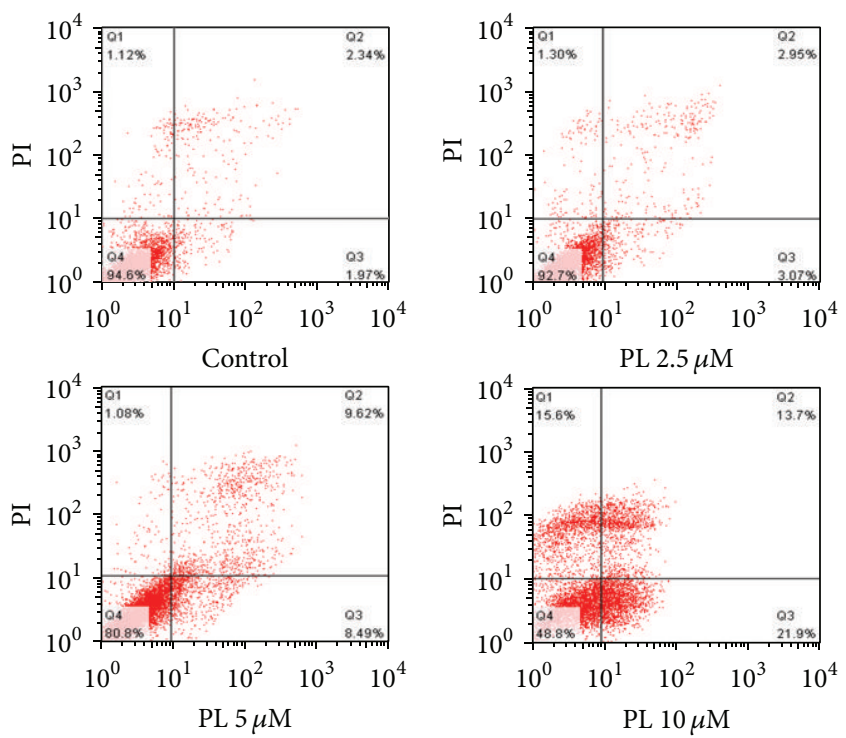

Annexin V-FITC

(a)

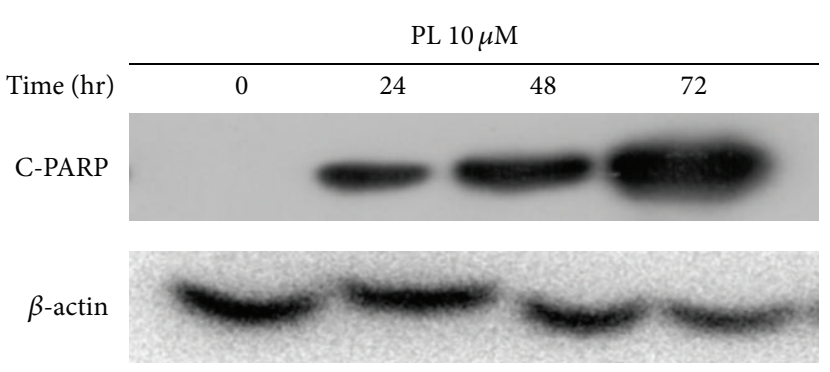

(c)

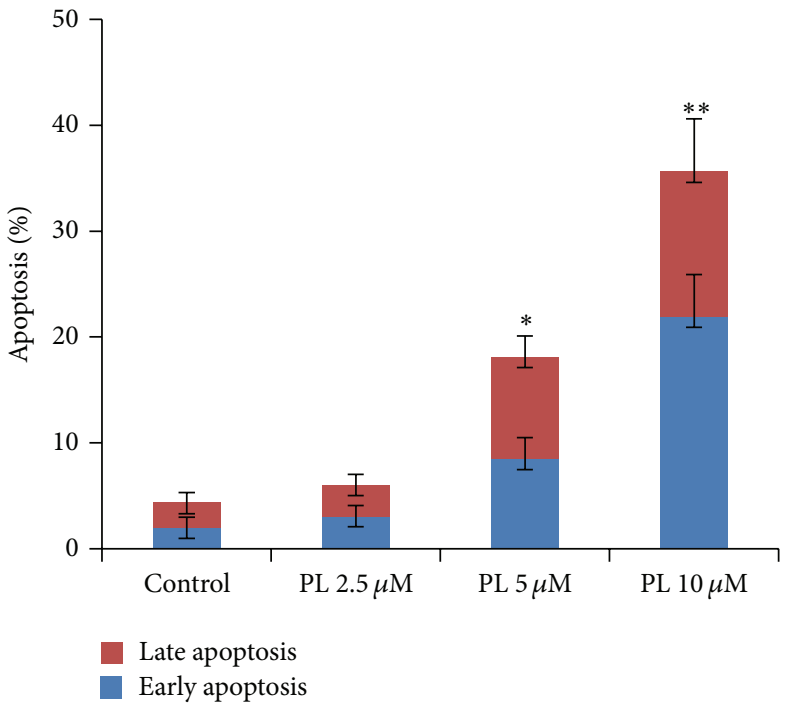

(b)

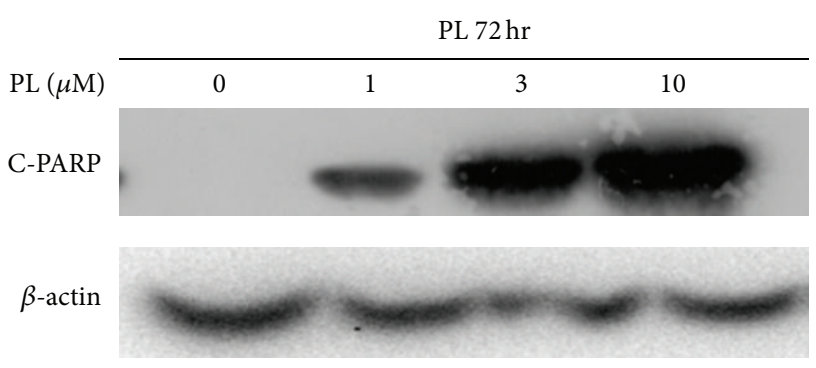

(d)

FIGURE 2: PL induced apoptosis in OVCAR3 ovarian cancer cells. (a) The results of cell apoptosis in PL-treated OVCAR3 cells. Cells were treated with the indicated concentration of PL for $48 \mathrm{hr}$, stained with Annexin V/PI, and examined by FCM. The proportions of Annexin $\mathrm{V}+/ \mathrm{PI}-$ and Annexin V+/PI+ cells indicated the early and late stages of apoptosis. (b) The quantified results of (a). (c) and (d) Representative Western blotting analysis of C-PARP in OVCAR3 cells treated with the indicated PL. $\beta$-actin was used as loading control. ${ }^{*} P<0.05$ and ${ }^{* *} P<0.01$ versus corresponding control.

length of $480 \mathrm{~nm}$ through FL-1 $(530 \mathrm{~nm})$ and FL-2 $(585 \mathrm{~nm})$ filters. The early apoptotic cells (Annexin V positive only) and late apoptotic cells (Annexin V and PI positive) were quantified.

2.4. Measurement of ROS Production. Cells were incubated with $10 \mu \mathrm{M}$ of DHE for $30 \mathrm{~min}$ at $37^{\circ} \mathrm{C}$, washed twice with PBS, and immediately microphotographed under a conventional fluorescent microscope (Olympus, Japan). For each well, 5 fields were taken randomly.

2.5. Cell Cycle Analysis. Cells were harvested and washed twice with cold PBS and then fixed with ice-cold 70\% (v/v) ethanol for $30 \mathrm{~min}$ at $4^{\circ} \mathrm{C}$. After centrifugation at $200 \times \mathrm{g}$ for $10 \mathrm{~min}$, cells were washed twice with PBS, resuspended with $0.5 \mathrm{~mL}$ PBS containing PI $(50 \mu \mathrm{g} / \mathrm{mL})$, Triton X-100
$(0.1 \%, \mathrm{v} / \mathrm{v}), 0.1 \%$ sodium citrate, and DNase-free RNase $(100 \mu \mathrm{g} / \mathrm{mL})$, and detected by FCM after 15 min incubation at room temperature in the dark. Fluorescence was measured at an excitation wave length of $480 \mathrm{~nm}$ through a FL-2filter $(585 \mathrm{~nm})$. Data were analyzed using ModFit LT 3.0 software (Becton Dickinson).

2.6. Western Blot Analysis. Cells were harvested and washed twice with cold PBS and then resuspended and lysed in RIPA buffer (1\% NP-40, 0.5\% sodium deoxycholate, $0.1 \%$ SDS, $10 \mathrm{ng} / \mathrm{mL}$ PMSF, $0.03 \%$ aprotinin, and $1 \mu \mathrm{M}$ sodium orthovanadate) at $4^{\circ} \mathrm{C}$ for $30 \mathrm{~min}$. Lysates were centrifuged for $10 \mathrm{~min}$ at $14,000 \times \mathrm{g}$ and supernatants were stored at $-80^{\circ} \mathrm{C}$ as whole cell extracts. Total protein concentrations were determined with Bradford assay. Proteins were separated on $12 \%$ SDS-PAGE gels and transferred to polyvinylidene 

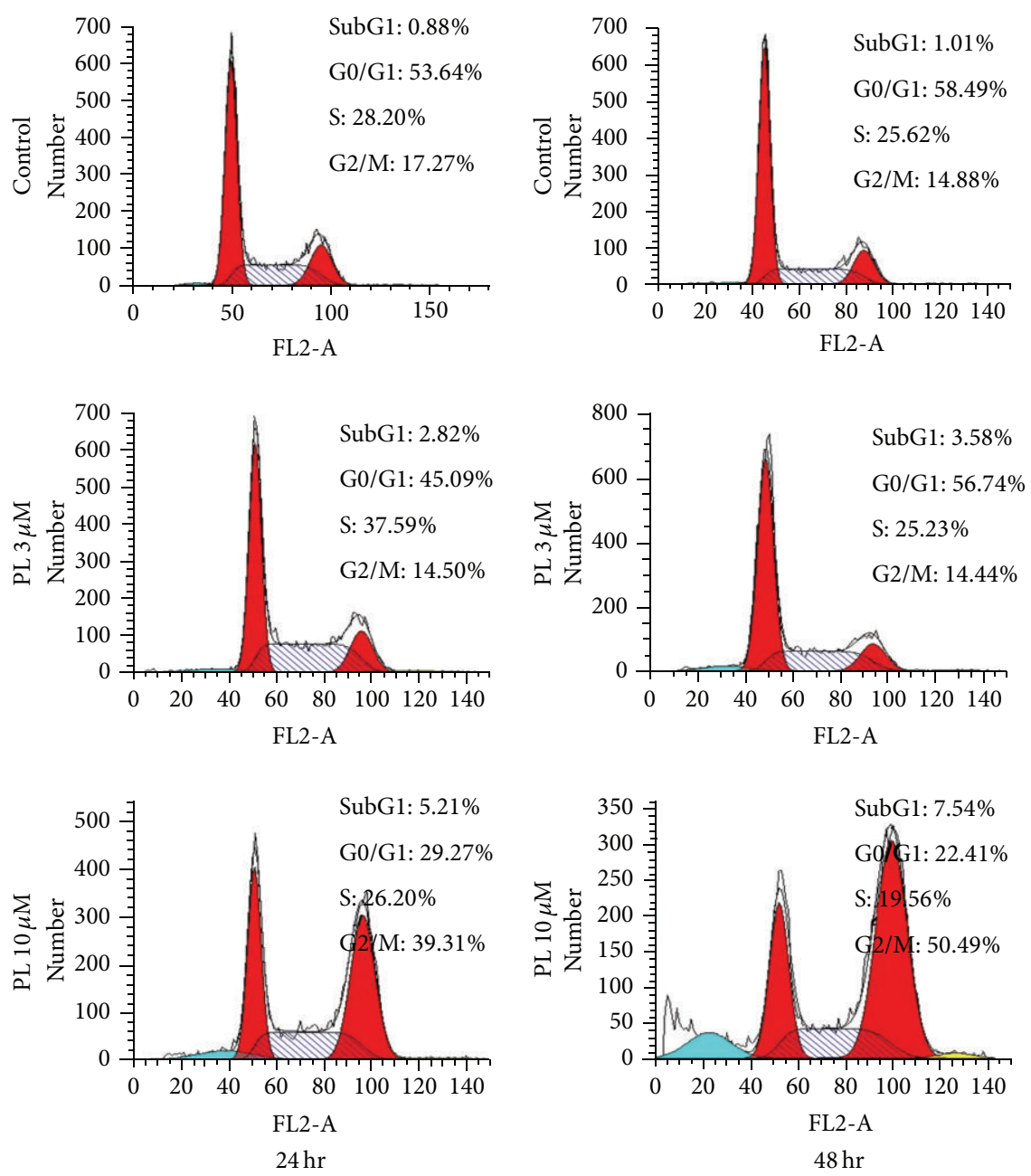

(a)

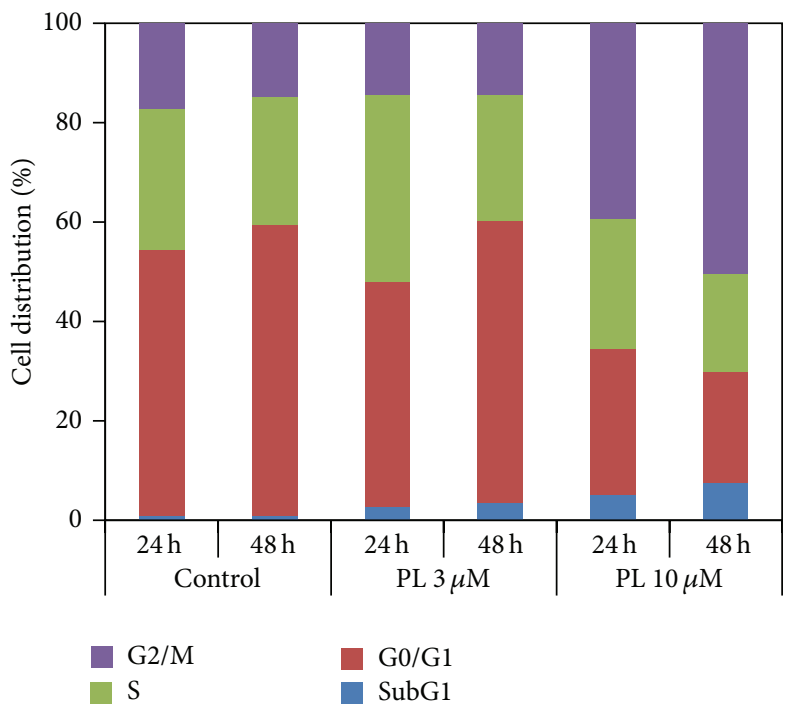

(b)

FIGURE 3: PL induced subG1 accumulation and G2/M arrest in OVCAR3 ovarian cancer cells. (a) The results of cell cycle distribution in PLtreated OVCAR3 cells. Cells were treated with the indicated PL, stained with PI, and examined by FCM. The percentages of subG1, G1/G0, S, and G2/M phase were calculated using ModFit LT 3.0 software. (b) The quantified results of (a). 

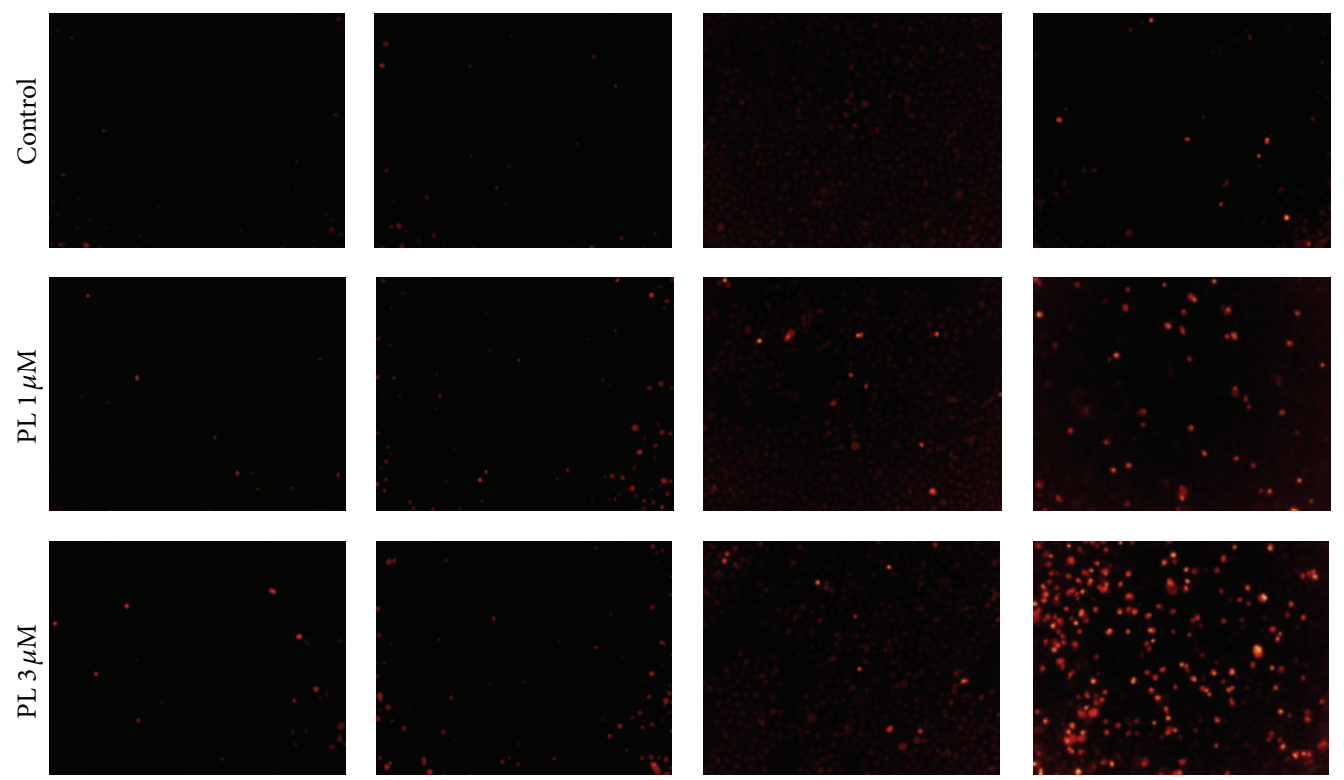

$12 \mathrm{hr}$

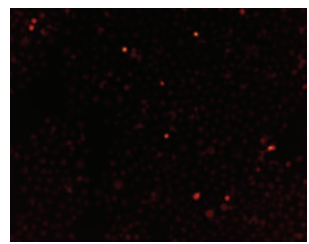

$24 \mathrm{hr}$

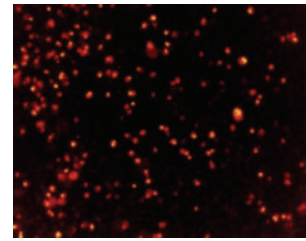

$48 \mathrm{hr}$

FIGURE 4: Piperlongumine induced ROS accumulation in OVCAR3 ovarian cancer cells. Cells were treated with PL as indicated, incubated with DHE, and microphotographed under a conventional fluorescent microscope.

difluoride membranes. Membranes were blocked with 5\% BSA and incubated with the indicated primary antibodies. Corresponding horseradish peroxidase-conjugated secondary antibodies were used against each primary antibody. Proteins were detected using the chemiluminescent detection reagents and films.

2.7. Statistical Analysis. All experiments were repeated at least 3 times and the differences were determined by using Student's $t$-test. The significance was determined at $P<0.05$.

\section{Results}

3.1. PL Selectively Inhibited the Growth of Ovarian Cancer Cells. To determine the effect of PL on ovarian cancer cells, three ovarian cancer cell lines A2780, OVCAR3, and SKOV3 and human embryonic kidney cell line HEK293T were treated with either the vehicle control (DMSO) or increasing concentrations of PL range from $1 \mu \mathrm{M}$ to $100 \mu \mathrm{M}$ for $72 \mathrm{hr}$. As shown in Figure 1(b), the results of MTT assay revealed that the growth of three ovarian cancer cell lines was similarly inhibited by PL in a concentration-dependent manner. The $\mathrm{IC}_{50}$ values of PL after $72 \mathrm{hr}$ exposure were $6.18 \mu \mathrm{M}, 6.20 \mu \mathrm{M}$, and $8.20 \mu \mathrm{M}$ in A2780, OVCAR3, and SKOV3, respectively (Figure 1(b)). However, PL showed the much weaker inhibition effect on the human normal HEK293T cells than three ovarian cancer cell lines and the $\mathrm{IC}_{50}$ values of PL were $60.23 \mu \mathrm{M}$ to HEK293T. These data suggested that PL selectively inhibits the growth of human ovarian cancer cells compared with normal cells.
3.2. PL Induced Apoptosis in OVCAR3 Ovarian Cancer Cells. To determine whether the growth inhibition of ovarian cancer cells by PL was due to the induction of apoptosis, cell apoptosis was assessed by FCM with Annexin V/PI staining. OVCAR3 cells were treated with the different concentrations of PL for $48 \mathrm{hr}$, stained with Annexin V/PI, and examined by FCM. As shown in Figures 2(a) and 2(b), PL treatment mostly induced apoptosis in OVCAR3 cells and both proportions of Annexin V+/PI- (early stage of apoptosis) and Annexin $\mathrm{V}+/ \mathrm{PI}+$ (late stage of apoptosis) cells were increased with the elevated PL concentrations.

To further detect the apoptosis induced by PL, the expression of apoptosis marker cleaved-PARP (C-PARP) proteins was analyzed by Western blot in OVCAR3 cells with or without PL treatment. Compared with the loading control $\beta$ actin proteins, the levels of C-PARP proteins in OVCAR3 cells were increased in a dose- and time-dependent manner after being treated with PL (Figures 2(c) and 2(d)). Together, these results indicated that the growth inhibition of PL on ovarian cancer cells might be due to the induction of apoptosis.

3.3. PL Induced SubG1 Accumulation and G2/M Arrest in OVCAR3 Ovarian Cancer Cells. In addition to the evaluation of PL-induced growth inhibition and proapoptosis effect, the effect of PL on cell cycle distribution was analyzed by FCM with PI staining. OVCAR3 cells were treated with PL $(3 \mu \mathrm{M}$ and $10 \mu \mathrm{M})$ for $24 \mathrm{hr}$ and $48 \mathrm{hr}$, stained with PI, and examined by FCM. The percentages of subG1, G1/G0, S, and G2/M phase were calculated using ModFit LT 3.0 software. Compared to the control groups, the subG1 and G2/M 


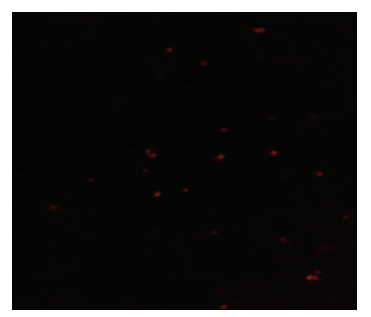

Control

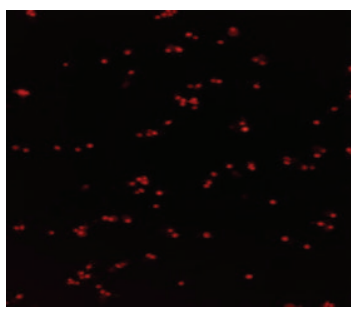

PL
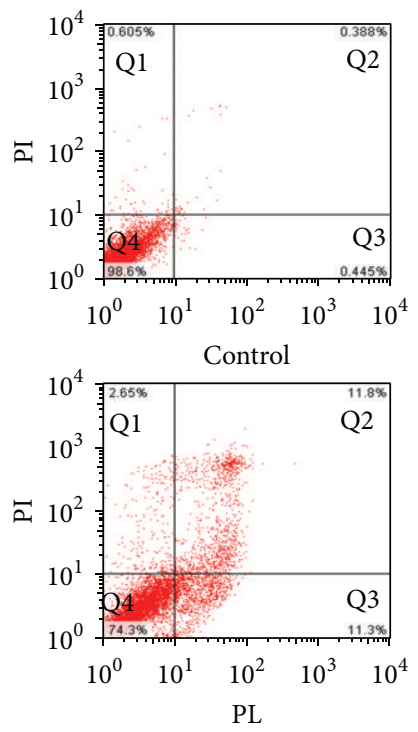

Annexin V-FITC

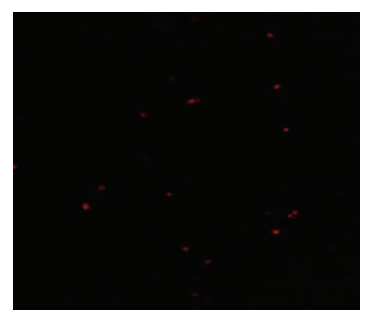

NAC

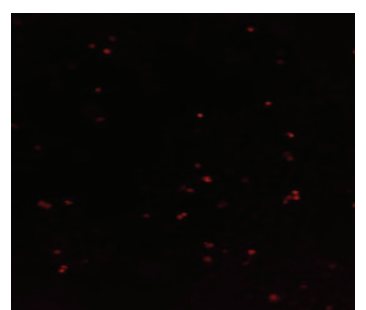

$\mathrm{NAC}+\mathrm{PL}$

(a)
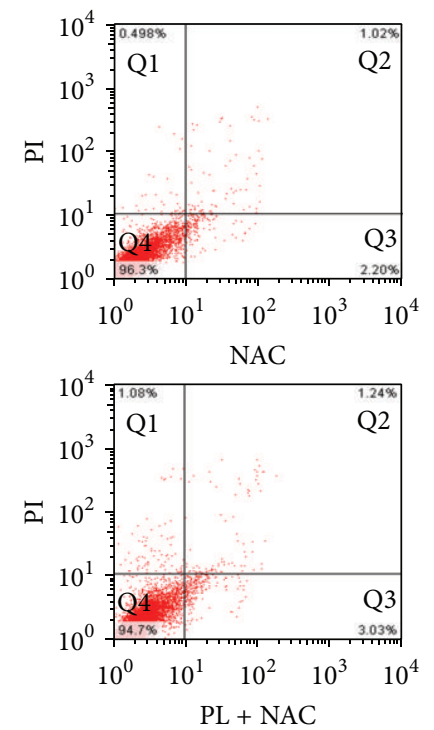

Annexin V-FITC

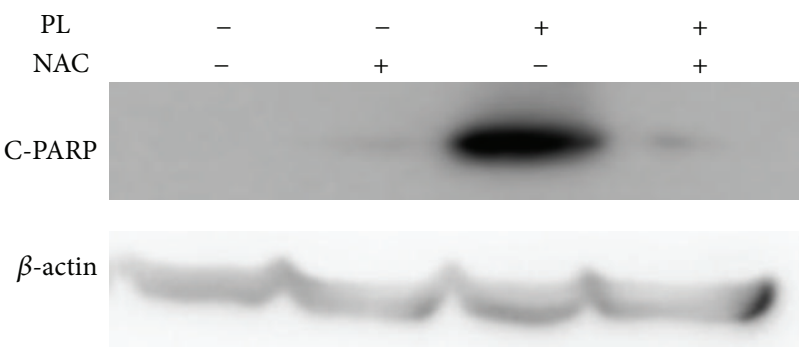

(b)

(c)

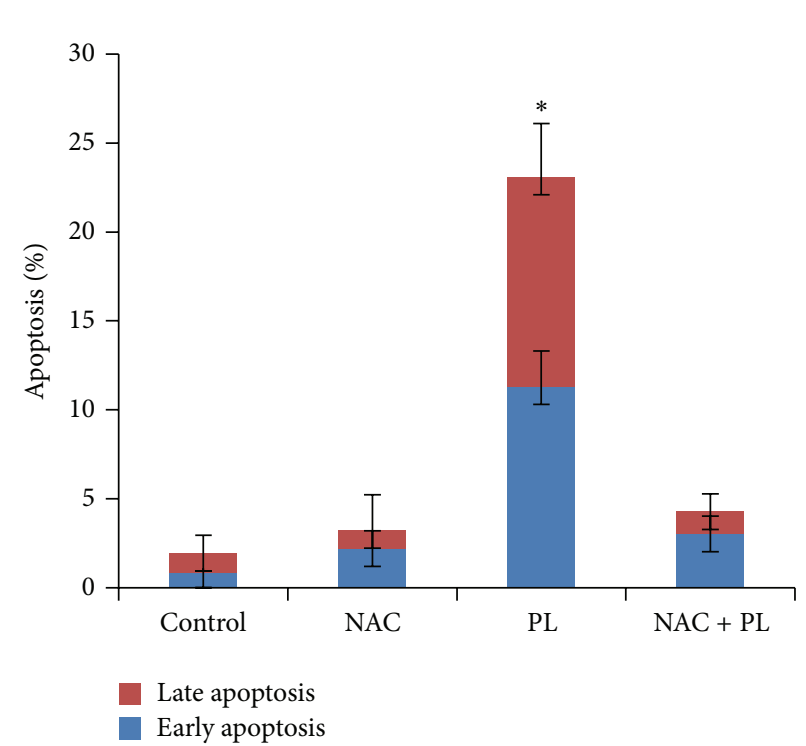

(d)

FIGURE 5: ROS generation was critical for PL-induced apoptosis in OVCAR3 ovarian cancer cells. (a) ROS accumulation and (c) cell apoptosis in PL-treated OVCAR3 cells were reversed by NAC. Cells were treated with PL $(10 \mu \mathrm{M})$ for $24 \mathrm{hr}$ in the presence or absence of 3 mM NAC pretreatment for $1 \mathrm{hr}$. The apoptosis was detected by FCM with Annexin V/PI staining and the expression of C-PARP proteins was analyzed by Western blot. (c) The quantified results of (d). (b) Representative Western blotting analysis of C-PARP in OVCAR3 cells treated as indicated. $\beta$-actin was used as loading control. ${ }^{*} P<0.05$ and ${ }^{* *} P<0.01$ versus corresponding control.

groups of PL-treated OVCAR3 cells were dose- and timedependently increased (Figures 3(a) and 3(b)). Therefore, the effect of PL on cell cycle distribution in OVCAR3 cells is the induction of subGl accumulation which indicated apoptosisassociated chromatin degradation and arrest of cell cycle in $\mathrm{G} 2 / \mathrm{M}$ phase.

3.4. ROS Generation Was Critical for PL-Induced Apoptosis in OVCAR3 Ovarian Cancer Cells. Numerous anticancer agents exhibit antitumor activity via ROS-dependent activation of apoptotic cell death [25] and it has previously been reported that the elevated intracellular ROS mediated PL-induced apoptosis in several human cancer cells (EJ, MDA-MB-231, U2OS, and MDA-MB-435) [18]. Dihydroethidium (DHE) is a classic ROS fluorescent probe, which can penetrate through living cell membrane freely and be oxidized by intracellular ROS to oxide ethidium that conjugated with DNA to emit the detectable red fluorescence. As shown in Figure 4, PL exposure resulted in a time- and concentration-dependent ROS accumulation in OVCAR3 cells. Significant intracellular ROS generation was observed when the cells were treated just 

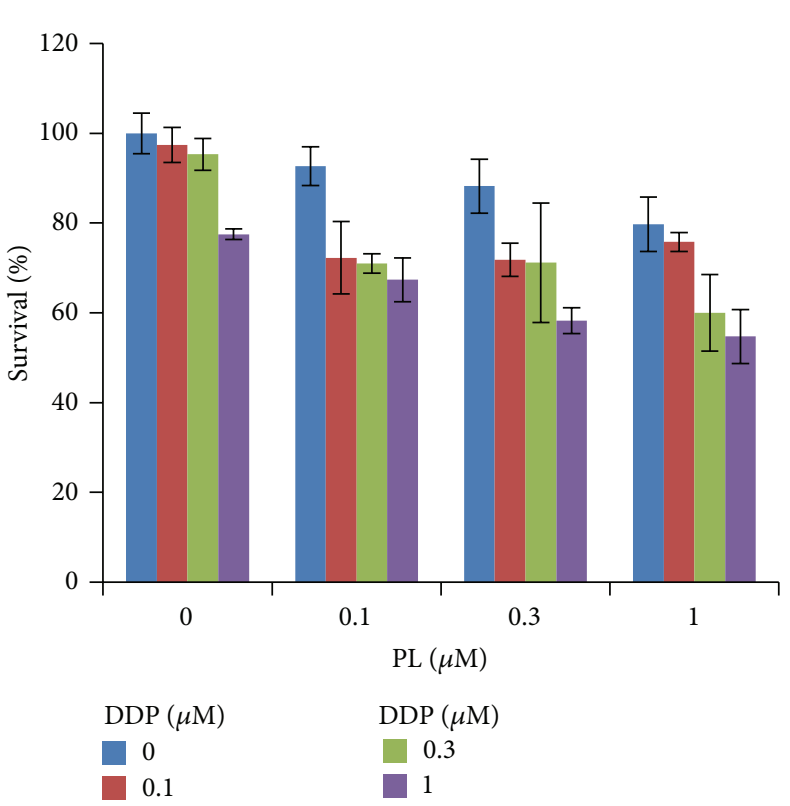

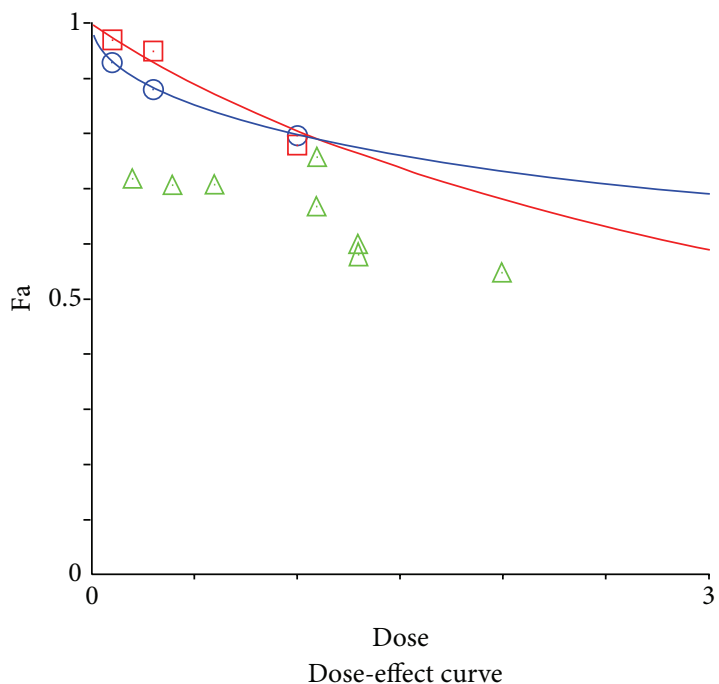

$\odot$ DDP

. $\mathrm{PL}$

$\triangle$ DDP-PL (a)

\begin{tabular}{llll}
\hline Dose DDP & Dose PL & Effect & CI \\
\hline 0.1 & 0.1 & 0.72 & 0.10380 \\
0.1 & 0.3 & 0.71 & 0.21173 \\
0.1 & 1.0 & 0.67 & 0.50065 \\
0.3 & 0.1 & 0.71 & 0.17589 \\
0.3 & 0.3 & 0.71 & 0.29072 \\
0.3 & 1.0 & 0.58 & 0.35704 \\
1.0 & 0.1 & 0.76 & 0.72203 \\
1.0 & 0.3 & 0.6 & 0.25800 \\
1.0 & 1.0 & 0.55 & 0.38399 \\
\hline
\end{tabular}

(c) (b)

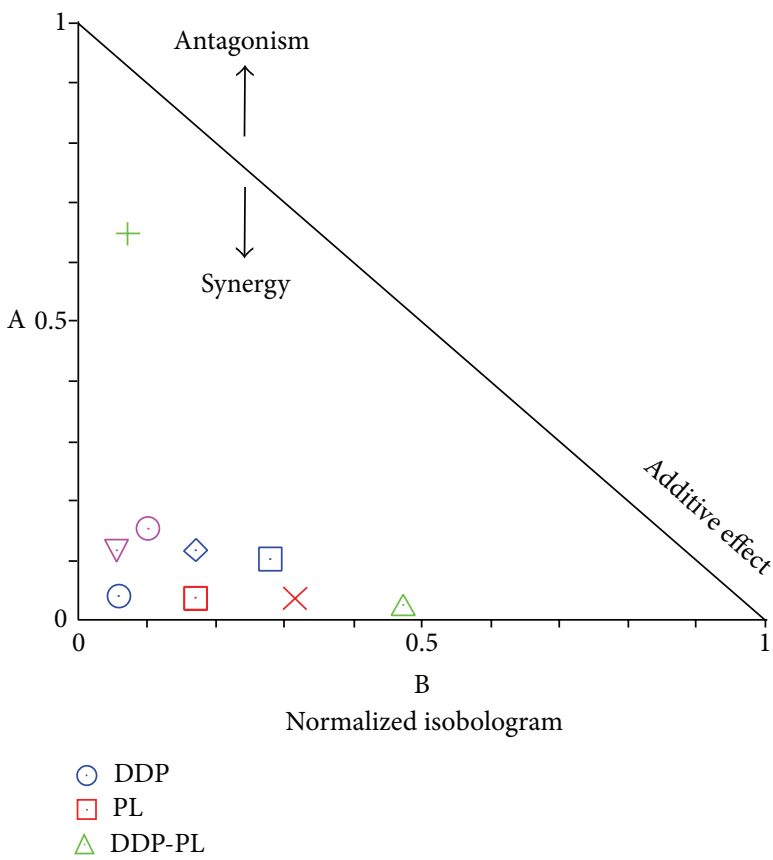

(d)

FIGURE 6: PL synergized with DDP in OVCAR3 ovarian cancer cells. (a) The growth histogram of OVCAR3 treated with the indicated PL and DDP. Cells were treated with PL (range from 0.1 to $1 \mu \mathrm{M})$ combined with DDP $(0.1$ to $1 \mu \mathrm{M}$ ) and cell survival was detected by MTT assay. The data were analyzed by CompuSyn software with the results showing dose-effect curve (b), CI values (c), and normalized isobologram (d).

for as little as $1 \mathrm{hr}$; ROS production was increasing and being maintained even at $48 \mathrm{hr}$, indicating a rapid and sustained generation of ROS in the PL-treated cells. As predicted, the PL-induced ROS accumulation was greatly reduced by NAC due to its ability to elevate intracellular glutathione to prevent the production of ROS (Figures 5(a) and 5(b)).
To further investigate the relationship between the ROS generation and PL-induced apoptosis, OVCAR3 cells were treated with PL $(10 \mu \mathrm{M})$ for $24 \mathrm{hr}$ in the presence or absence of $3 \mathrm{mM}$ NAC pretreatment for $1 \mathrm{hr}$. The apoptosis was detected by FCM with Annexin V/PI staining and the expression of C-PARP proteins was analyzed by Western blot. As shown 


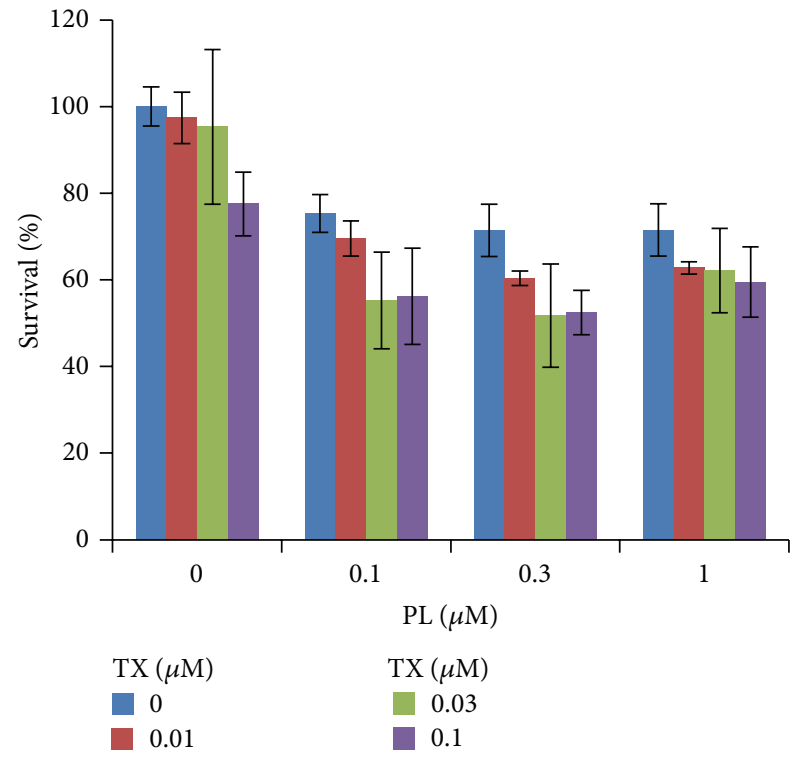

(a)

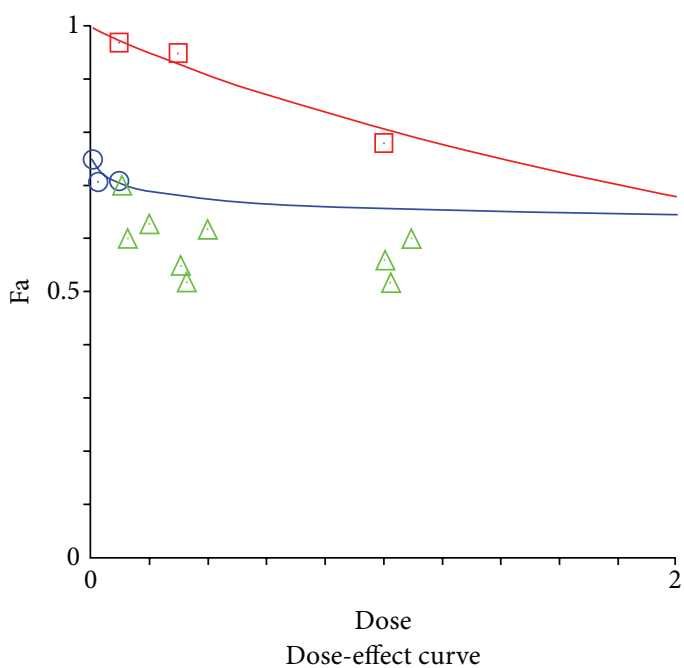

$\odot$ TX

$\square$ PL

$\triangle$ TX-PL

Dose-effect curve

\begin{tabular}{llll}
\hline Dose TX & Dose PL & Effect & CI \\
\hline 0.01 & 0.1 & 0.7 & 0.13944 \\
0.01 & 0.3 & 0.55 & 0.08402 \\
0.01 & 1.0 & 0.56 & 0.29193 \\
0.03 & 0.1 & 0.6 & 0.03616 \\
0.03 & 0.3 & 0.52 & 0.07415 \\
0.03 & 1.0 & 0.52 & 0.24709 \\
0.1 & 0.1 & 0.63 & 0.06198 \\
0.1 & 0.3 & 0.62 & 0.12699 \\
0.1 & 1.0 & 0.6 & 0.35115 \\
\hline
\end{tabular}

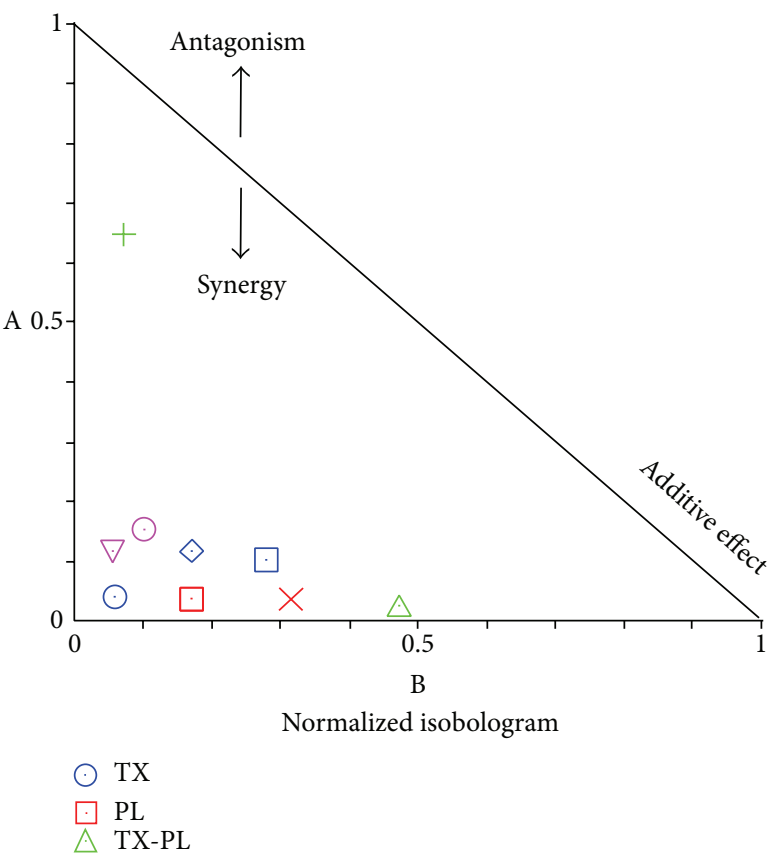

(c)

(d)

FIGURE 7: PL synergized with TX in OVCAR3 ovarian cancer cells. (a) The growth histogram of OVCAR3 treated with the indicated PL and TX. Cells were treated with PL (range from 0.1 to $1 \mu \mathrm{M})$ combined with TX $(0.01$ to $0.1 \mu \mathrm{M})$ and cell survival was detected by MTT assay. The data were analyzed by CompuSyn software with the results showing dose-effect curve (b), CI values (c), and normalized isobologram (d).

in Figures 5(c) and 5(d), PL-induced apoptosis and the increased expression of C-PARP proteins were completely blocked by NAC. These data suggested that ROS generation is critical for PL-induced apoptosis in OVCAR3 ovarian cancer cells.
3.5. PL Synergized with DDP or TX in OVCAR3 Ovarian Cancer Cells. Combinations of agents at low doses can reduce side effects of chemotherapy and improve the compliance of patients with chemotherapy; thus investigating novel agents for combination chemotherapy to overcome drug resistance 
and achieve better therapeutic effects is of vital significance. For example, a new synthetic compound phenoxodiol exerted potent anticancer activity combined with DDP against ovarian cancer [26]. Currently, DDP and TX are the two of main chemotherapeutic drugs for ovarian cancer in clinic. The present study tested whether lower dose of two drugs in combination (PL + DDP or PL + TX) was able to exert a synergistic antitumor activity compared to PL, DDP, or TX treatment alone. OVCAR3 cells were treated with PL (range from 0.1 to $1 \mu \mathrm{M})$ combined with DDP $(0.1$ to $1 \mu \mathrm{M})$ or TX $(0.01$ to $0.1 \mu \mathrm{M})$ and cell survival was detected by MTT assay. As shown in Figures 6 and 7, the cell survival was decreased in the combination of lower dose PL with either DDP or TX. The CI values of both combination were $<1$, suggesting that the antigrowth effect of combination is synergistic rather than additive. These observations demonstrated that PL was able to sensitize OVCAR3 ovarian cancer cells to both DDP and TX.

\section{Discussion}

In this report, we firstly demonstrated that PL selectively mediated time- and concentration-dependent antigrowth effects on human ovarian cancer cells. The $\mathrm{IC}_{50}$ value after $72 \mathrm{hr}$ treatment with PL ranges from 6 to $8 \mu \mathrm{M}$ in three human ovarian cancer cell lines, was similar to the $\mathrm{IC}_{50}$ value of PL in other solid cancers [14]. The results of FCM analysis showed that PL treatment increased both early and later stage of apoptosis, subG1 accumulation and G2/M phase arrest. Inhibition of the intercellular ROS accumulation by NAC could totally block PL-induced apoptosis. Moreover, PL synergistically enhanced the antigrowth effect of DDP or TX, which suggested that PL might be a potential chemosensitizer for ovarian cancer chemotherapy.

The intracellular production of ROS greatly contributes to the regulation of cell survival and death [27]. Although cancer cells become well adapted to persistent intrinsic oxidative stress, a further increase in ROS above the toxic threshold level may result in cell death [28]. Chemotherapeutical agents including DDP, TX and etoposide induce apoptotic cell death by increasing the intracellular ROS levels. However, continuous DDP treatment may reduce cellular ROS levels and cancer cells may become drug resistant. The chemoresistance of ovarian cancer was also linked to increased cellular glutathione content [29]. Furthermore, an elevation of the cellular ROS level by exogenous ROS generation in combination with DDP resensitized drug-resistant cancer cells [30]. It has been postulated that PL kills carcinoma cells by targeting their "nononcogene codependency" on elevated antioxidative defense pathways acquired in response to cell transformation-induced oxidative stress [18]. Our findings on ovarian cancer cells have suggested that PL-mediated growth inhibition was related to $\mathrm{G} 2 / \mathrm{M}$ phase arrest and apoptosis by the increasing intercellular ROS. Previously reported, a dose-dependent decrease of cdc-2 expression but not cyclinB1 changing was associated with PL-mediated cell cycle arrest in PC-3 cells [16]. The present study has attributed the generation of ROS to the proapoptotic effect of PL in ovarian cancer cells, which was in agreement with the previous findings in other cancer cell types $[12,18]$.

Altogether, the present study offers the first evidence that PL selectively inhibited cell growth and induced ROSdependent cell apoptosis and G2/M cell cycle arrest in human ovarian cancer. Furthermore, PL synergizes with DDP and TX to inhibit the growth of human ovarian cancer cells. Further in vivo experiments may aid in the confirmation of the therapeutic efficacy of this agent for patients with ovarian cancer.

\section{Conflict of Interests}

The authors declare that they have no conflict of interests.

\section{Authors' Contribution}

Li-Hua Gong and Xiu-Xiu Chen contributed equally to the work.

\section{Acknowledgments}

This work was supported by funds from the Chinese National Natural Science Foundation no. 31271444 and no. 81201726 (Zhi Shi), the Foundation for Research Cultivation and Innovation of Jinan University no. 21612407 (Zhi Shi), the Specialized Research Fund for the Doctoral Program of Higher Education no. 20124401120007 (Zhi Shi), Science and Technology Program of Guangzhou no. 14200010 (Zhi Shi), the Scientific Research Foundation of the Education Department of Zhejiang Province, China, no. Y201016398 (Xiao-Jian Yan), and the Natural Science Foundation of Zhejiang Province, China, no. LQ12H16004 (Xiao-Jian Yan).

\section{References}

[1] J. Permuth-Wey and T. A. Sellers, "Epidemiology of ovarian cancer," Methods in Molecular Biology, vol. 472, pp. 413-437, 2009.

[2] S. A. Cannistra, "Cancer of the ovary," The New England Journal of Medicine, vol. 351, no. 24, pp. 2519-2529, 2004.

[3] L. Chen, L. Liang, X. Yan et al., "Survivin status affects prognosis and chemosensitivity in epithelial ovarian cancer," International Journal of Gynecological Cancer, vol. 23, no. 2, pp. 256-263, 2013.

[4] X.-J. Yan, L.-Z. Liang, Z.-Y. Zeng, Z. Shi, and L.-W. Fu, "Effect of survivin shRNA on chemosensitivity of human ovarian cancer cell line OVCAR3 to paclitaxel," Ai Zheng, vol. 25, no. 4, pp. 398403, 2006.

[5] X.-J. Yan, L.-Z. Liang, Z.-Y. Zeng, L.-W. Fu, and Z. Shi, "Influence of short hairpin RNA on survivin mRNA expression and chemosensitivity to paclitaxel in ovarian cancer cells," Zhonghua Fu Chan Ke Za Zhi, vol. 40, no. 9, pp. 609-613, 2005.

[6] X. J. Yan, L. H. Gong, F. Y. Zheng, K. J. Cheng, Z. S. Chen, and Z. Shi, "Triterpenoids as reversal agents for anticancer drug resistance treatment," Drug Discovery Today, 2013.

[7] C. K. Bose, "Follicle stimulating hormone receptor in ovarian surface epithelium and epithelial ovarian cancer," Oncology Research Featuring Preclinical and Clinical Cancer Therapeutics, vol. 17, no. 5, pp. 231-238, 2008. 
[8] T. P. Szatrowski and C. F. Nathan, "Production of large amounts of hydrogen peroxide by human tumor cells," Cancer Research, vol. 51, no. 3, pp. 794-798, 1991.

[9] P. T. Schumacker, "Reactive oxygen species in cancer cells: live by the sword, die by the sword," Cancer Cell, vol. 10, no. 3, pp. 175-176, 2006.

[10] J. Fang, T. Seki, and H. Maeda, "Therapeutic strategies by modulating oxygen stress in cancer and inflammation," Advanced Drug Delivery Reviews, vol. 61, no. 4, pp. 290-302, 2009.

[11] Y. Q. Xue, J. M. Di, Y. luo, K. J. Cheng, X. Wei, and Z. Shi, "Resveratrol oligomers for the prevention and treatment of cancers," Oxidative Medicine and Cellular Longevity, vol. 2014, Article ID 765832, 9 pages, 2014.

[12] D. P. Bezerra, C. Pessoa, M. O. de Moraes, N. Saker-Neto, E. R. Silveira, and L. V. Costa-Lotufo, "Overview of the therapeutic potential of piplartine (piperlongumine)," European Journal of Pharmaceutical Sciences, vol. 48, no. 3, pp. 453-463, 2013.

[13] D. P. Bezerra, G. C. G. Militão, F. O. de Castro et al., "Piplartine induces inhibition of leukemia cell proliferation triggering both apoptosis and necrosis pathways," Toxicology in Vitro, vol. 21, no. 1, pp. 1-8, 2007.

[14] D. P. Bezerra, C. Pessoa, M. O. de Moraes et al., "Antiproliferative effects of two amides, piperine and piplartine, from Piper species," Zeitschrift fur Naturforschung C: Journal of Biosciences, vol. 60, no. 7-8, pp. 539-543, 2005.

[15] J. M. Liu, F. Pan, L. Li et al., "Piperlongumine selectively kills glioblastoma multiforme cells via reactive oxygen species accumulation dependent JNK and p38 activation," Biochemical and Biophysical Research Communications, vol. 437, no. 1, pp. 8793, 2013.

[16] E.-H. Kong, Y.-J. Kim, Y.-J. Kim et al., "Piplartine induces caspase-mediated apoptosis in PC-3 human prostate cancer cells," Oncology Reports, vol. 20, no. 4, pp. 785-792, 2008.

[17] D. P. Bezerra, F. O. De Castro, A. P. N. N. Alves et al., "In vitro and in vivo antitumor effect of 5-FU combined with piplartine and piperine," Journal of Applied Toxicology, vol. 28, no. 2, pp. 156-163, 2008.

[18] L. Raj, T. Ide, A. U. Gurkar et al., "Selective killing of cancer cells by a small molecule targeting the stress response to ROS," Nature, vol. 475, no. 7355, pp. 231-234, 2011.

[19] D. J. Adams, M. J. Dai, G. Pellegrino et al., "Synthesis, cellular evaluation, and mechanism of action of piperlongumine analogs," Proceedings of the National Academy of Sciences of the United States of America, vol. 109, no. 38, pp. 15115-15120, 2012.

[20] D. P. Bezerra, D. J. Moura, R. M. Rosa et al., "Evaluation of the genotoxicity of piplartine, an alkamide of Piper tuberculatum, in yeast and mammalian V79 cells," Mutation ResearchGenetic Toxicology and Environmental Mutagenesis, vol. 652, no. 2, pp. 164-174, 2008.

[21] P. Makhov, K. Golovine, E. Teper et al., "Piperlongumine promotes autophagy via inhibition of Akt/mTOR signalling and mediates cancer cell death," British Journal of Cancer, vol. 110, pp. 899-907, 2014.

[22] Y. Wang, J. W. Wang, X. Xiao et al., "Piperlongumine induces autophagy by targeting p38 signaling," Cell Death and Disease, vol. 4, p. e824, 2013.

[23] Z. Shi, Y.-J. Liang, Z.-S. Chen et al., "Reversal of MDR1/Pglycoprotein-mediated multidrug resistance by vector-based RNA interference in vitro and in vivo," Cancer Biology \& Therapy, vol. 5, no. 1, pp. 39-47, 2006.
[24] C. S. Weil, "Tables for convenient calculation of medianeffective dose (LD50 or ED50) and instructions in their use," Biometrics, vol. 8, no. 1, pp. 249-263, 1952.

[25] J. Fang, H. Nakamura, and A. K. Iyer, "Tumor-targeted induction of oxystress for cancer therapy," Journal of Drug Targeting, vol. 15, no. 7-8, pp. 475-486, 2007.

[26] D.-A. Silasi, A. B. Alvero, T. J. Rutherford, D. Brown, and G. Mor, "Phenoxodiol: pharmacology and clinical experience in cancer monotherapy and in combination with chemotherapeutic drugs," Expert Opinion on Pharmacotherapy, vol. 10, no. 6, pp. 1059-1067, 2009.

[27] M. Ott, V. Gogvadze, S. Orrenius, and B. Zhivotovsky, "Mitochondria, oxidative stress and cell death," Apoptosis, vol. 12, no. 5, pp. 913-922, 2007.

[28] J. P. Fruehauf and F. L. Meyskens Jr., "Reactive oxygen species: a breath of life or death?" Clinical Cancer Research, vol. 13, no. 3, pp. 789-794, 2007.

[29] S. Okuno, H. Sato, K. Kuriyama-Matsumura et al., "Role of cystine transport in intracellular glutathione level and cisplatin resistance in human ovarian cancer cell lines," British Journal of Cancer, vol. 88, no. 6, pp. 951-956, 2003.

[30] A. K. Maiti, "Gene network analysis of oxidative stress-mediated drug sensitivity in resistant ovarian carcinoma cells," The Pharmacogenomics Journal, vol. 10, no. 2, pp. 94-104, 2010. 


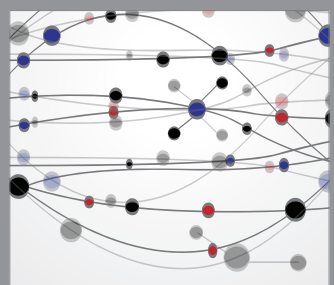

The Scientific World Journal
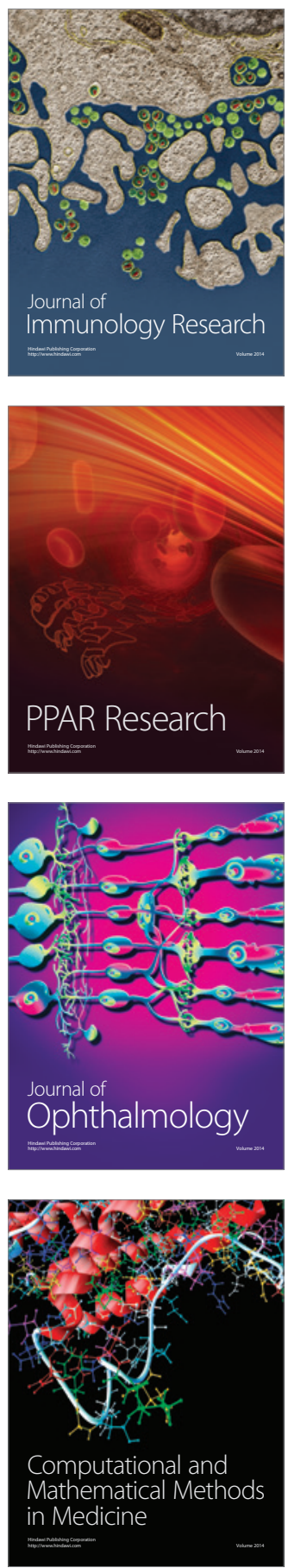

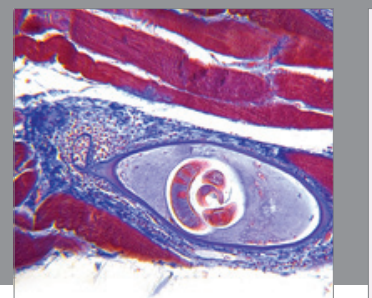

Gastroenterology

Research and Practice
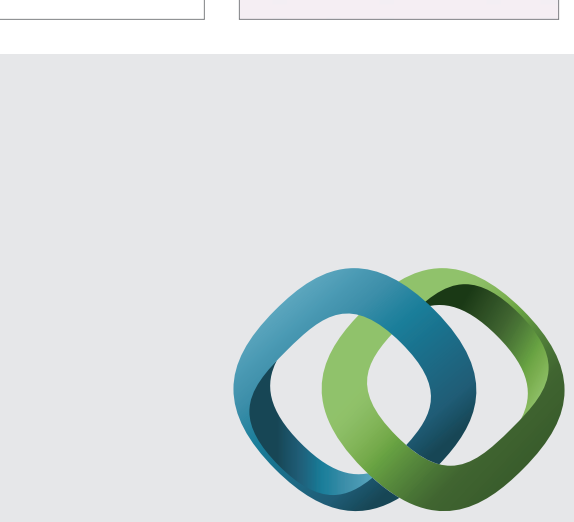

\section{Hindawi}

Submit your manuscripts at

http://www.hindawi.com
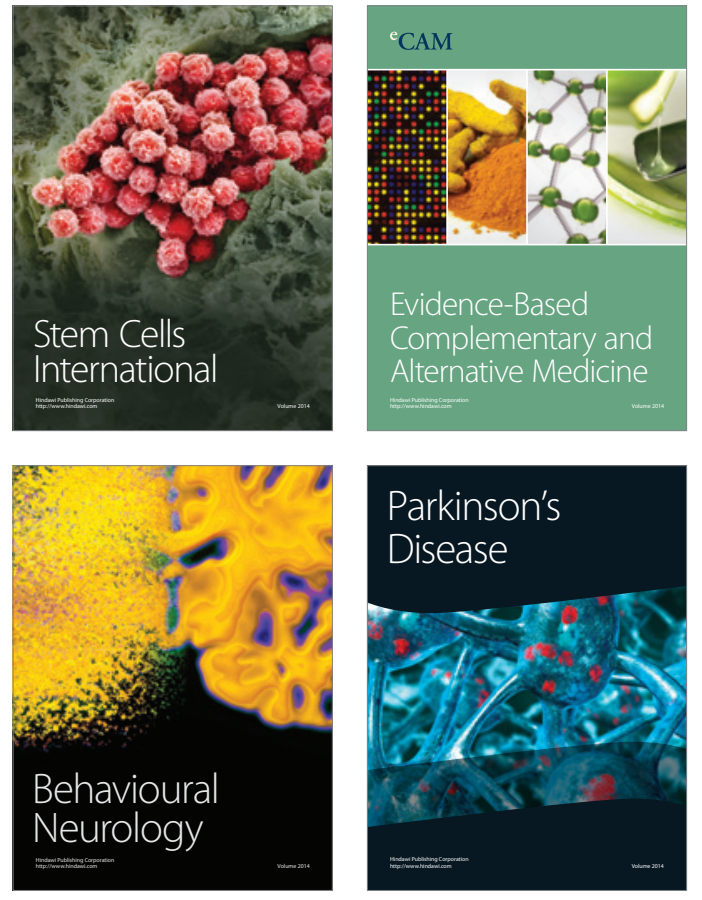
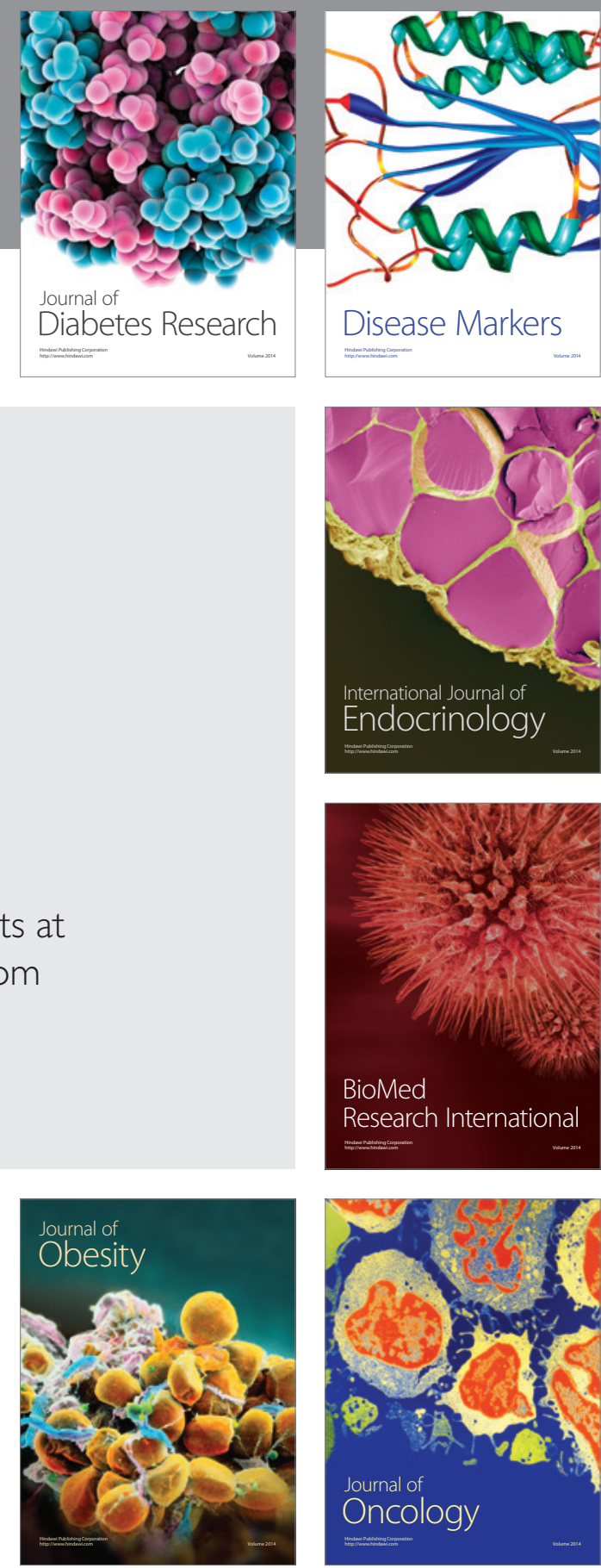

Disease Markers
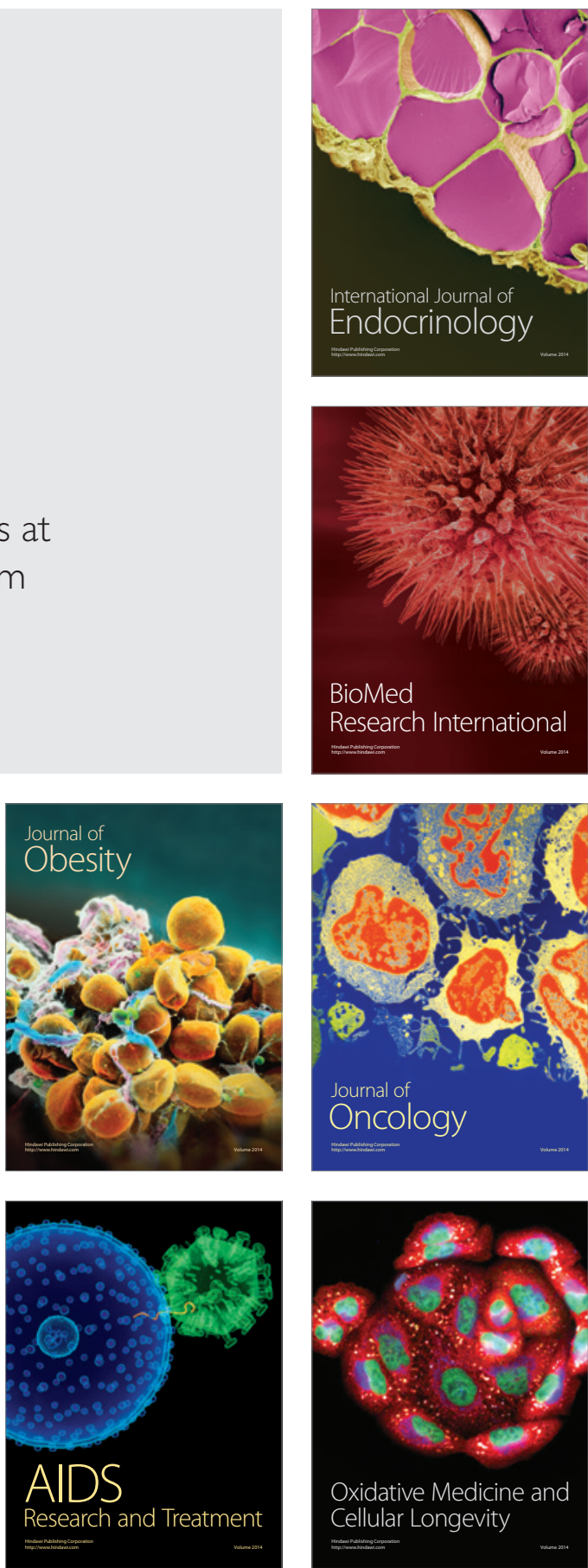